\title{
Percepção de comerciantes sobre o gerenciamento de resíduos sólidos urbanos em Araçuaí/MG
}

Questões ambientais, como o gerenciamento de resíduos sólidos, estão cada vez mais presentes no cotidiano da população e no ambiente comercial. Neste contexto, o presente artigo teve como objetivo conhecer a percepção dos comerciantes sobre o gerenciamento de sólidos urbanos no município de Araçuaí, Nordeste de Minas Gerais. Para isto, foi aplicado um questionário com dez questões a 62 indivíduos atuantes no comércio. Os resultados demonstraram que a maioria dos entrevistados são compostos por funcionários (81,94\%), seguidos de gerentes $(12,50 \%)$ e proprietários $(5,56 \%)$. Segundo a maioria dos comerciantes, a responsabilidade dos resíduos é do município, que é realizado meio do serviço limpeza pública e acredita que o aterro sanitário é melhor destino dos resíduos gerados nos estabelecimentos comerciais. Os comerciantes têm ciência dos termos: coleta seletiva e produtos recicláveis e conferiram-nos muita importância. No entanto, não os aplicam e não têm conhecimento sobre os materiais destinados à logística reversa. Desta forma, conclui-se que a percepção dos comerciantes de Araçuaí/MG sobre o gerenciamento de resíduos sólidos é restrita, sendo refletida nos cuidados deles quanto aos resíduos sólidos produzidos em seus estabelecimentos comerciais. Com isto, propõe-se a adoção de instrumentos previsto na Política Nacional de Resíduos Sólidos, tais como: programas de educação ambiental voltada à temática, promoção da coleta seletiva, bem como envio de resíduos a associação de catadores local e o estímulo à logística reversa.

Palavras-chave: Gestão Ambiental; Resíduos Sólidos Urbanos; Coleta Seletiva; Comércio.

\section{Perception of traders on urban solid waste management in Araçuaí/MG}

\begin{abstract}
Environmental problems, such as solid waste management, are increasingly present in the the population lives and in the commercial environment. In this context, this article aims to know the traders' perception about the management of urban solids in the city of Araçuaí, Northeast of Minas Gerais. For this, a questionnaire with ten questions was applied to 62 individuals active in the trade. The results shows that the majority of respondents are employees (81.94\%), followed by managers $(12.50 \%)$ and owners $(5.56 \%)$. According to the majority of the merchants, the responsibility for the waste lies with the municipality, which is performed through the public cleaning service, and the landfill is the best destination for waste generated in commercial establishments. Traders are aware of the terms selective collection and recyclables and have given them a lot of importance. However, they do not apply them and they are unaware of reverse logistics materials. Thus, it is concluded that the perception of Araçuaí/MG merchants about solid waste management is restricted, being reflected in their care regarding solid waste produced in their commercial establishments. It is proposed to adopt instruments provided for in the National Solid Waste Policy, such as environmental education programs focused on the theme, promotion of selective collection, as well as the sending of waste to the local waste pickers' association and the encouragement of reverse logistics.
\end{abstract}

Keywords: Environmental Management; Urban solid waste; Selective collect; Trade.

Topic: Desenvolvimento, Sustentabilidade e Meio Ambiente

Reviewed anonymously in the process of blind peer.
Received: 19/07/2019

Approved: 24/10/2019
Manamares de Souza Coutinho Lopes Instituto Federal de Minas Gerais, Brasil http://lattes.cnpq.br/7410310849682599 http://orcid.org/0000-0002-4752-4501 manamares@gmail.com

Carlos Augusto Pereira da Silva (D)

Instituto Federal do Norte de Minas Gerais, Brasil http://lattes.cnpq.br/2843639478540582 http://orcid.org/0000-0001-8949-3152

carlos.augusto@ifnmg.edu.br

Eliane Macedo Sobrinho Santos (iD)

Instituto Federal do Norte de Minas Gerais, Brasil

http://lattes.cnpq.br/0451966994155112

http://orcid.org/0000-0002-1576-4957

eliane.santos@ifnmg.edu.br

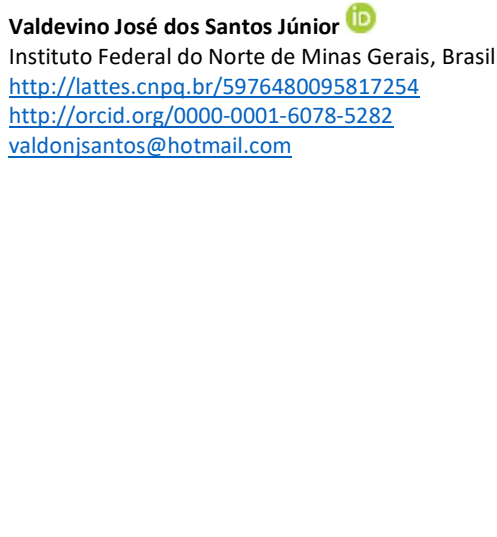

Referencing this:

LOPES, M. S. C.; SILVA, C. A. P.; SANTOS, E. M. S.; SANTOS JÚNIOR, V. J.. Percepção de comerciantes sobre o gerenciamento de resíduos sólidos urbanos em Araçuaí/MG. Natural Resources, v.9, n.3, p.10-17, 2019. DOI: http://doi.org/10.6008/CBPC2237-9290.2019.003.0002 


\section{INTRODUÇÃO}

Atualmente, a produção e a destinação de resíduos sólidos urbanos (RSU) têm causado grande preocupação à sociedade. É crescente a quantidade de novos produtos lançados no mercado, como também o número de embalagens descartadas. Isto favorece a geração de um grande volume de resíduos a serem depositados em aterros sanitários ou em lugares impróprios, provocando impactos socioambientais e refletindo em efeitos danosos ao homem e aos ecossistemas. Esta realidade pode ser observada tanto em grandes centros urbanos como em municípios de médio e pequeno porte (GOUVEIA, 2012; OLIVEIRA et al., 2012; SOLIANI et al., 2019). O gerenciamento dos resíduos sólidos (GRS) é definido pela Política Nacional de Resíduos Sólidos (PNRS), Lei 12.305/2010, como:

o conjunto de ações exercidas, direta ou indiretamente, nas etapas de coleta, transporte, transbordo, tratamento e destinação final ambientalmente adequada dos resíduos sólidos e disposição final ambientalmente adequada dos rejeitos, de acordo com plano municipal de gestão integrada de resíduos sólidos ou com plano de gerenciamento de resíduos sólidos. (BRASIL, 2010).

No gerenciamento de resíduos sólidos são incluídas atividades visando à redução de resíduos na fonte, à coleta seletiva e reciclagem, à compostagem de resíduos orgânicos, à construção de aterros sanitários e outras formas de destinação final de resíduos não recicláveis. Tendo em vista o desenvolvimento sustentável, o GRS tem sido considerado a solução mais eficiente para a destinação ambientalmente adequada dos resíduos (BELTRAME et al., 2012).

O conhecimento da percepção da população sobre a gestão dos resíduos sólidos no local em que habitam é relevante, pois permite diagnosticar o nível de informação da população sobre a temática. É por meio da percepção que o indivíduo toma consciência do mundo, estando relacionado à aprendizagem e sensibilização envolvidos nos processos de educação ambiental (MENGHINI, 2005). No entanto, a percepção de comerciantes sobre o GRS tem sido pouco explorada, necessitando maior atenção para o preenchimento dessa lacuna. Neste contexto, o presente artigo tem como objetivo avaliar a percepção de comerciantes sobre o gerenciamento de resíduos sólidos urbanos no município de Araçuaí, Nordeste de Minas Gerais.

\section{METODOLOGIA}

\section{Área de estudo}

O presente estudo foi realizado no município de Araçuaí, situado na microrregião do Médio Jequitinhonha, no Nordeste de Minas Gerais (Figura 1). O município possui uma população de 36.013 habitantes, com extensão territorial de $2.236,279 \mathrm{~km}^{2}$ (IBGE, 2010).

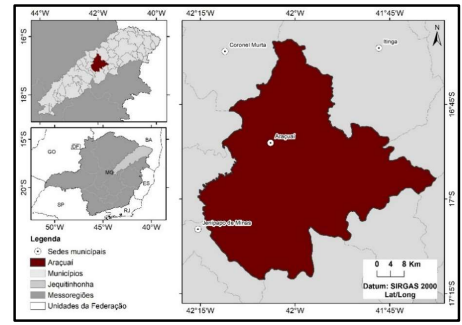

Figura 1: Localização município de Araçuaí, Minas Gerais. 


\section{Coleta dos dados}

Este artigo, cujo estudo se caracteriza como descritivo, é de caráter exploratório (MARKONI et al., 2010) e busca obter a opinião de comerciantes acerca do gerenciamento de resíduos sólidos urbanos. A coleta de dados foi realizada mediante a aplicação de 62 questionários estruturados aos indivíduos atuantes no comércio, isto é, comerciantes do município de Araçuaí, segundo os pressupostos teóricos de Gil (2014). As dez perguntas do questionário tinham como objetivo identificar os indivíduos atuantes no comércio e verificar o conhecimento deles acerca da temática gerenciamento de resíduos sólidos.

Investigou-se com o questionário o conhecimento dos participantes acerca dos seguintes termos: coleta seletiva, produtos recicláveis, responsabilidade pela coleta de resíduos, melhor destinação e hábito na separação de resíduos e modelo de coleta seletiva. Além disso, buscou-se saber quais itens eram os mais indicadores para reuso e/ou reciclagem; qual era a importância de reciclar o lixo; e quais produtos comercializados deviam ser devolvidos. Os comerciantes optaram por apenas uma das alternativas.

A escolha dos participantes da pesquisa se deu de forma abrangente, englobando nove tipos de segmentos comerciais de modo a assegurar a solidez e a confiabilidade dos resultados (SOUSA et al., 2016). O estudo de caso apresentado consiste em um instrumento fundamental que pode auxiliar a implantação de programas de gerenciamento dos resíduos sólidos, permitindo aumentar o conhecimento por meio do trabalho de campo, com aplicação de questionários para o levantamento de informações e para a apresentação de um quadro das atuais condições da sociedade (OLIVEIRA et al., 2012).

\section{RESULTADOS E DISCUSSÃO}

Foram respondidos 62 questionários por comerciantes de diferentes estabelecimentos, distribuídos em nove segmentos comerciais, sendo eles: dez em lojas de confecção e calçados, dez em lojas de confecção, dez em lojas de variedades, nove em farmácias, sete em sapatarias, seis em supermercados, quatro em papelarias, quatro em lojas de ferragens e dois em lojas de materiais de construção. Do montante dos entrevistados, $81,94 \%$ eram funcionários, $12,50 \%$ eram gerentes e 5,56\% proprietários (Gráfico 1). Os entrevistados foram questionados sobre o conhecimento do termo 'coleta seletiva'. Observou-se que 95,16\% afirmaram conhecer o termo, enquanto 4,84\% o desconhecem (Gráfico 2).

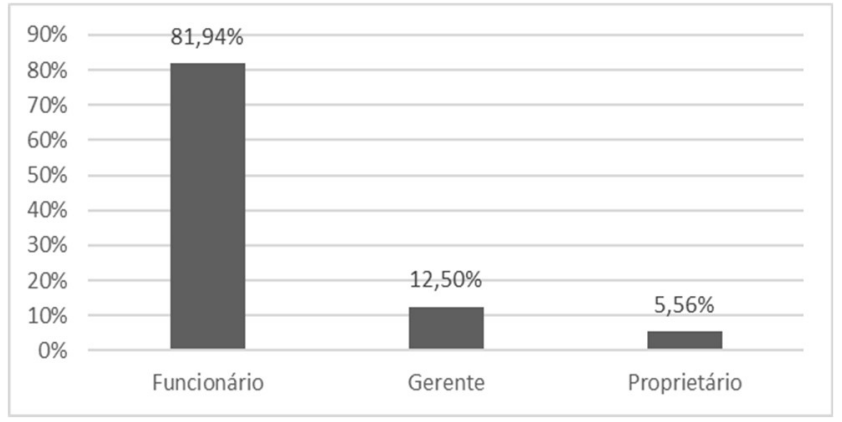

Gráfico 1: Identificação dos entrevistados.

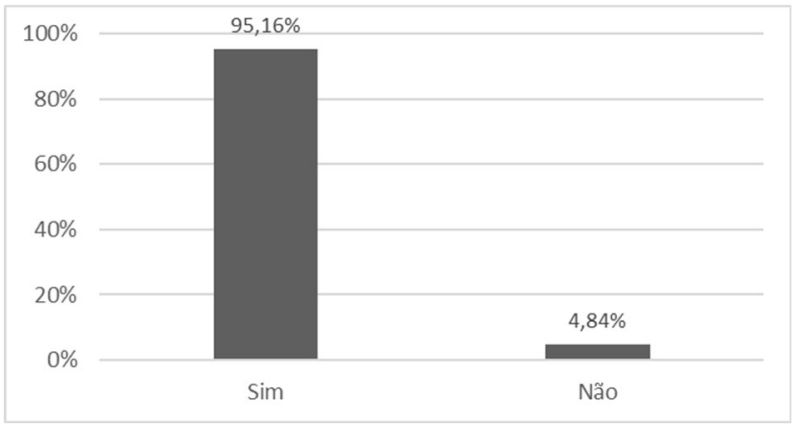

Gráfico 2: Conhecimento acerca do termo Coleta seletiva.

Sousa et al. (2016), em um estudo realizado no bairro Jardim Santarém, em Santarém/PA, sobre o 
conhecimento do termo 'coleta seletiva', constatou que 54,13\% dos entrevistados afirmaram não saber do que se tratava e $45,87 \%$ afirmaram ter ciência. O não conhecimento do termo coletiva seletiva é preocupante, pois constitui um dos instrumentos propostos pela PNRS para o eficiente gerenciamento de resíduos sólidos, comprometendo, portanto, as etapas fundamentais do gerenciamento, tais como: reciclagem e reaproveitamento de materiais.

Beltrame et al. (2013), ao questionar gestores ambientais sobre a coleta seletiva no âmbito de organizações e instituições, afirmaram que tal prática está relacionada à imagem das empresas diante da sociedade, uma vez que, quando uma empresa realiza programas ambientalmente corretos, a sua imagem se eleva. Sobre o hábito de separação de resíduos sólidos no estabelecimento comercial, 69,35\% dos comerciantes responderam que não separam e 30,65\% afirmaram que realizam a separação dos resíduos, conforme o Gráfico 3.

Este resultado aponta que, apesar de grande parte dos comerciantes conhecerem o termo 'coleta seletiva' (95,16\%, apresentado no Gráfico 1), não é a maioria que aplica a coleta seletiva, isto é, que separa os resíduos sólidos em seus estabelecimentos comerciais. A prática de separar resíduos sólidos na fonte, de forma direta, é de suma importância para preservar as características dos resíduos, possibilitando-os de serem enviados às usinas de reciclagem, ou de serem reaproveitados por alguma associação ou cooperativa de catadores (PEDRINI et al., 2007; SOUSA et al., 2016).

Beltrame et al. (2013) relataram se que cerca de $60 \%$ de gestores ambientais de empresas acreditam que a coleta seletiva traz benefícios ao meio ambiente de forma direta. Quanto ao grau de relação entre a coleta seletiva de resíduos sólidos e a questão socioambiental, aproximadamente $70 \%$ acreditam ser diretamente proporcional.

De forma indireta, o gerenciamento inadequado de resíduos sólidos impossibilita o cumprimento dos demais segmentos do saneamento, inviabilizando o tratamento de águas residuárias e de abastecimento humano, comprometendo o sistema de drenagem pluvial urbano e acarretando enchentes e inundações. Além disso, os resíduos que são depositados em áreas de risco em centros urbanos podem ocasionar desmoronamento e risco de vida às famílias que ocupam áreas inapropriadas para urbanização (PEDRINI et al., 2007). Questionou-se os comerciantes sobre a responsabilidade da coleta dos resíduos gerados no estabelecimento comercial. 84\% disseram ser do município e 16\% da União (Gráfico 4).

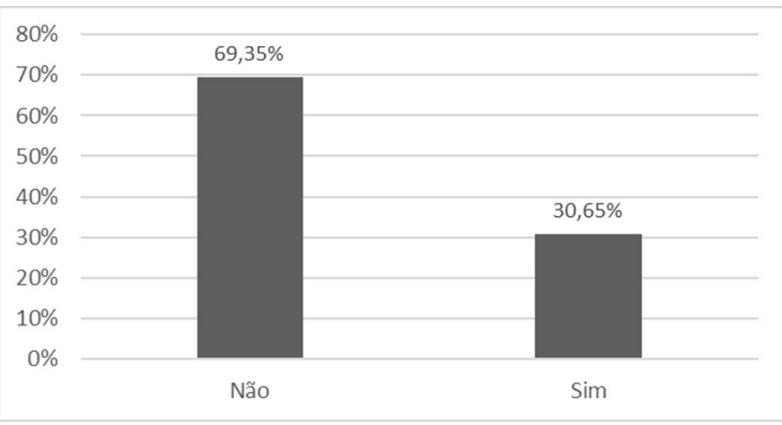

Gráfico 3: Separação de resíduos pelos comerciantes.

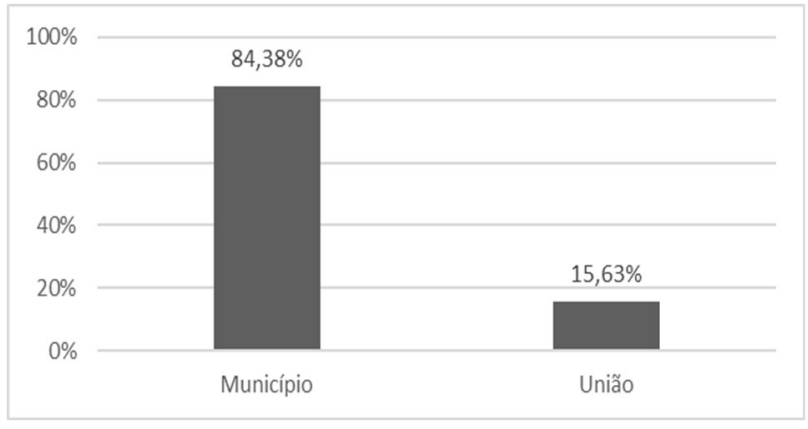

Gráfico 4: Responsabilidade de coleta dos resíduos gerados pelos estabelecimentos comerciais. 
Acerca da responsabilidade pelo gerenciamento de resíduos, verifica-se que os comerciantes, em geral, desconhecem um dos instrumentos da PNRS, a 'responsabilidade compartilhada', definida como:

um conjunto de atribuições individualizadas e encadeadas dos fabricantes, importadores, distribuidores e comerciantes, dos consumidores e dos titulares dos serviços públicos de limpeza urbana e de manejo dos resíduos sólidos, para minimizar o volume de resíduos sólidos e rejeitos gerados, bem como para reduzir os impactos causados à saúde humana e à qualidade ambiental decorrentes do ciclo de vida dos produtos. (BRASIL, 2010).

Reconhecer a necessidade de responsabilidade compartilhada é fundamental para o avanço do GRS de resíduos no país, uma vez que a destinação adequada dos resíduos depende do trabalho de todos os atores envolvidos na cadeia, tais como: consumidores, comerciantes, setor público e fabricantes (DEMAJOROVIC et al., 2013).

Sendo assim, o GRS no município começará a avançar quando comerciantes e consumidores perceberem a importância do compartilhamento de responsabilidades relacionada ao ciclo de vida dos produtos, destinando os resíduos de forma adequada pela coleta seletiva. Quanto ao destino dos resíduos, $83,56 \%$ dos comerciantes realizam o serviço de limpeza urbana, sendo que $16,44 \%$ afirmam fazer a coleta seletiva em seu estabelecimento (Gráfico 5).

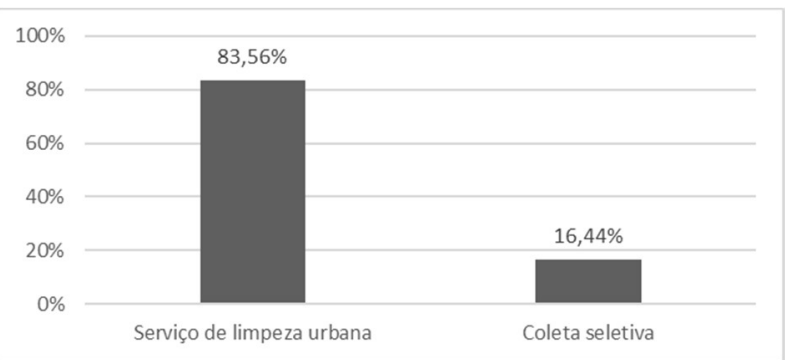

Gráfico 5: Destinação dos resíduos sólidos.

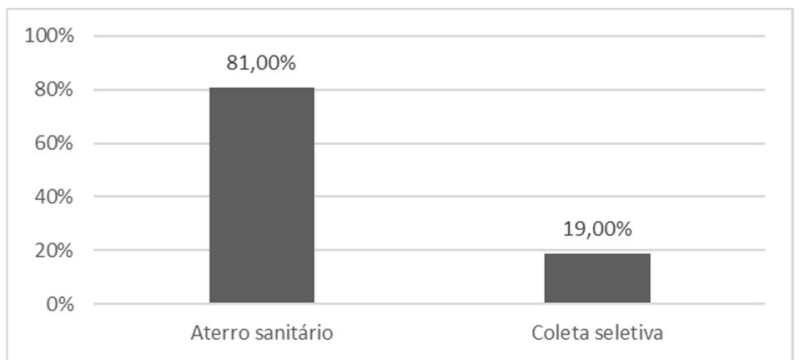

Gráfico 6: Melhor destinação aos resíduos sólidos.

Sobre a melhor destinação dos resíduos, 81\% responderam que seria o envio ao aterro sanitário e 19\% apontaram a coleta seletiva (Gráfico 6). Não foram apontados a realização da queima ou destinação dos resíduos em lotes vagos. Isto demonstra que os comerciantes destinam adequadamente os resíduos sólidos gerados em seus estabelecimentos comerciais, porém mais de $80 \%$ não fazem qualquer tipo de gerenciamento dos resíduos antes de enviarem a destinação final (aterro municipal).

A coleta dos resíduos domiciliares na área urbana é realizada em média duas a três vezes por semana em cada bairro, de segunda a sábado, por um caminhão prensa e dois caminhões basculantes. São coletados diretamente pelo serviço de limpeza urbana 59,75\% dos resíduos gerados, em sua maioria acondicionados em sacolas plásticas e destinados ao aterro controlado do município; 5,79\% são colocados em caçambas estacionárias de coleta; 31,39\% são queimados nas propriedades (residências); e 2,36\% recebem outra destinação (IBGE, 2010). Na zona rural não há coleta pela prefeitura municipal. No âmbito da definição do termo 'produtos recicláveis', 87,10\% dos comerciantes responderam que são aqueles que podem ser reutilizados, 9,68\% são aqueles que não podem ser utilizados e 1,61\% são aqueles que devem ser enviados a hospitais, conforme o Gráfico 7. 


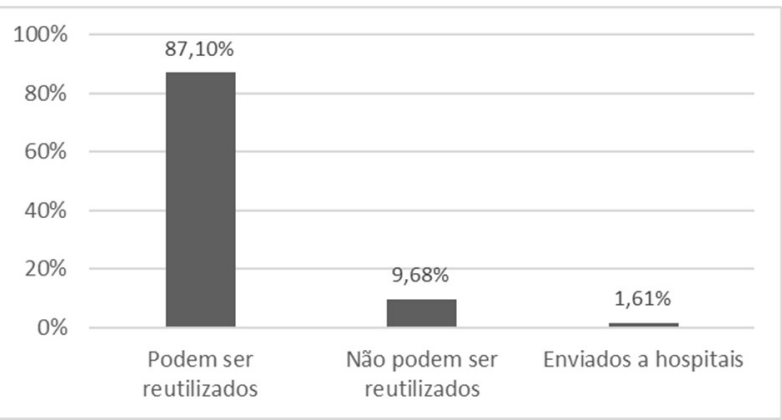

Gráfico 7: Definição de produtores recicláveis.

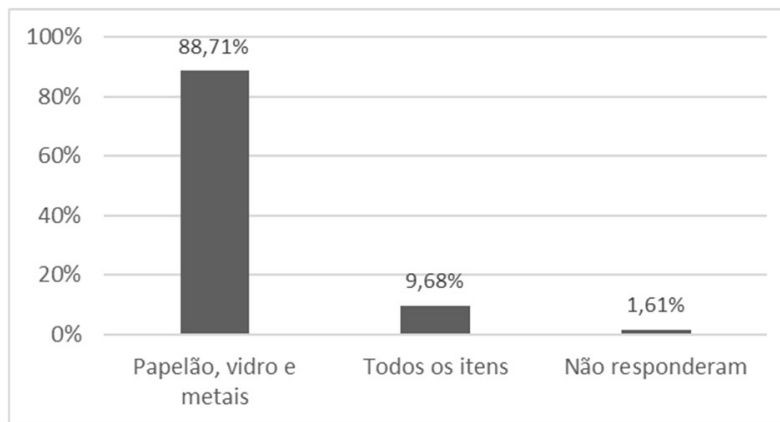

Gráfico 8: Materiais mais indicados para reciclagem.

Indagados sobre a importância da reciclagem, 100\% dos comerciantes apontaram ser muito importante reciclar. Quanto aos produtos mais indicados para a reciclagem, $88,71 \%$ responderam o papelão, o vidro e os metais; 9,68\% apontaram todos os itens (produtos químicos; papelão, vidro e metais; qualquer material de origem eletrônica) e 1,61\% não responderam.

No contexto da logística reversa, os comerciantes foram questionados sobre os produtos que comercializavam e quais deviam retornar ao fabricante. $29 \%$ apontaram os plásticos e os papelões, $27 \%$ as pilhas, as baterias, as lâmpadas florescentes e os medicamentos, e $39 \%$ apontaram nenhum dos produtos anteriores (Gráfico 9).

As respostas do Gráfico 9 demonstram que os comerciantes, em geral, têm pouco conhecimento sobre a logística reversa, dado pelo número de entrevistados. 39\% afirmaram que nenhum tipo de resíduo deve ser direcionado aos sistemas de logística reversa. Isso demonstra que um trabalho de conscientização ambiental com os comerciantes acerca dos sistemas de logística reversa é necessário, pois trata-se de um instrumento estabelecido em lei. Isto pode ser um reflexo da falta de conhecimento sobre o assunto que também está atrelado à falta de uma definição da responsabilidade de cada ator no ciclo de vida dos produtos.

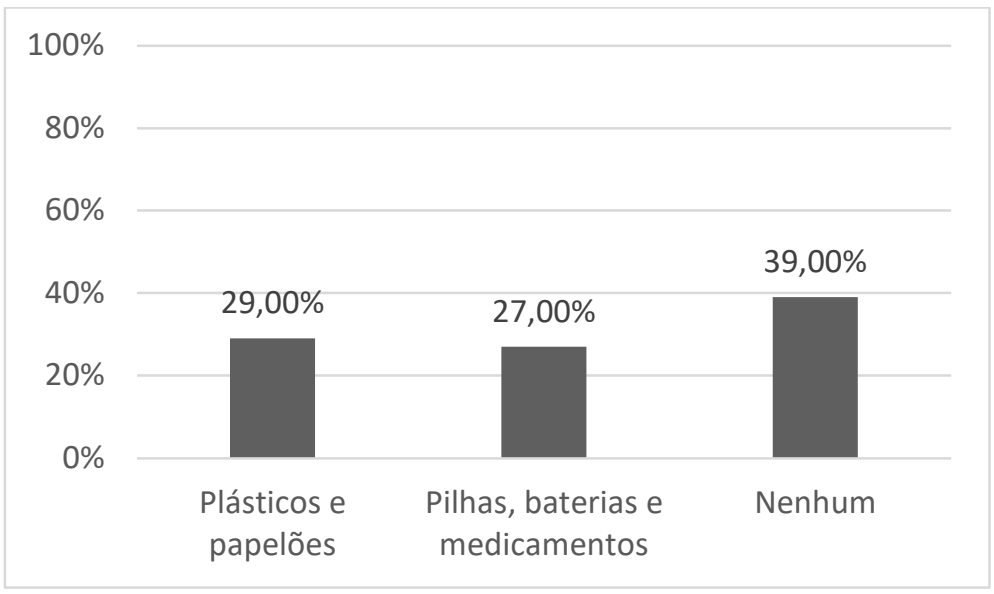

Gráfico 9: Materiais e logística reversa.

A PNRS define que os segmentos obrigados a estruturar e a implementar programas de logística reversa são os de "agrotóxicos e seus resíduos de embalagens, pilhas e baterias, pneus, óleos lubrificantes e seus resíduos em embalagens, lâmpadas fluorescentes, de vapor de sódio e mercúrio e de luz mista e; produtos eletroeletrônicos e seus componentes" (BRASIL, 2010), como uma das formas de operacionalizar a responsabilidade compartilhada. 
De maneira específica, a Resolução 401/2008, do Conselho Nacional do Meio Ambiente (CONAMA), determina que pilhas e baterias devem possuir processos de logística reversa. Está prevista também a realização de campanhas de educação ambiental e difusão de informações sobre o pós-consumo, que devem ser incentivadas por fabricantes importadores, distribuidores, comerciantes, em parceria com o poder público e a sociedade civil, visando promover a participação do consumidor nesse processo (CONAMA, 2008).

Os medicamentos e as embalagens não estão expressamente escritos no texto da lei ou do seu regulamento, mas podem ser enquadrados na aplicação de logística reversa de produtos e embalagens com impacto à saúde pública e ao meio ambiente (THODE FILHO et al., 2015). As ações de gerenciamento de medicamentos no Brasil ainda ocorrem de forma isolada, faltando uma comunicação entre os fabricantes, distribuidores de medicamentos e as companhias de coleta de resíduos (OLIVEIRA et al., 2019). Esta previsão também se aplica às embalagens em geral e está amparada pelas disposições do $\S 1^{\circ}$, art. 33 da PNRS (BRASIL, 2010).

\section{CONCLUSÃO}

Conclui-se que a percepção dos comerciantes de Araçuaí/MG sobre o gerenciamento de resíduos sólidos urbanos é restrita, a qual se reflete nos cuidados que eles têm para com o GRS produzidos em seus estabelecimentos comerciais. A maioria dos comerciantes tem ciência dos termos 'coleta seletiva' e 'produtos recicláveis', dando grande importância à reciclagem. Apesar de alguns declararem realizar coleta seletiva, a maioria dos entrevistados não realizam a separação dos resíduos antes da destinação final e tem pouco conhecimento e/ou aplicação de instrumentos da previstos na PNRS, como: coleta seletiva, materiais recicláveis e, principalmente, a logística reversa e os materiais por ela englobados.

Com isto, propõe-se adotar instrumentos previstos na PNRS, como: projetos de educação ambiental aos comerciantes, a fim de adquirir e apurar seus conhecimentos sobre a temática, melhorar suas ações diante do GRS e o possível envio desses resíduos a associações de catadores locais. Pode-se, ainda, estimular a interlocução entre empresas, indústrias e comerciantes acerca da logística reversa, visando promovê-la de forma eficaz.

\section{REFERÊNCIAS}

BELTRAME, T. F.; LHAMBY, A.. Coleta seletiva: percepção e conhecimento sobre o tema: uma pesquisa exploratória. REMOA, v.12, n.12, 2013.

BRASIL. Lei n. 12.305 de $\mathbf{2}$ de agosto de 2010. Institui a Política Nacional de Resíduos Sólidos, altera a Lei no 9.605, de 12 de fevereiro de 1998 e dá outras providências. Brasília: DOU, 2010.

CONAMA. Conselho Nacional de Meio Ambiente. Resolução CONAMA n. 401/2008. Estabelece os limites máximos de chumbo, cádmio e mercúrio para pilhas e baterias comercializadas no território nacional e os critérios e padrões para o seu gerenciamento ambientalmente adequado, e dá outras providências. Brasília: DOU, 2008.
DEMAJOROVIC, J.; MIGLIANO, J. E. B.. Política nacional de resíduos sólidos e suas implicações na cadeia da logística reversa de microcomputadores no brasil. Gestão \& Regionalidade, v.29, n.87, 2013.

GIL, A. C.. Métodos e técnicas de pesquisa social. 6 ed. São Paulo: Atlas, 2014

GOUVEIA, N.. Resíduos sólidos urbanos: impactos socioambientais e perspectiva de manejo sustentável com inclusão social. Ciência \& Saúde Coletiva, v.17, n.6, p.15031510, 2012.

IBGE. Instituto Brasileiro de Geografia e Estatística. Panorama. Rio de Janeiro: IBGE, 2010. 
MARCONI, M. A.; LAKATOS, E. M.. Fundamentos de metodologia cientifica. 7 ed. São Paulo: Atlas, 2010.

MENGHINI, F. B.. As trilhas interpretativas como recurso pedagógico: caminhos traçados para a educação ambiental. Dissertação (Mestrado em Educação) - Universidade do Vale de Itajaí, 2005.

OLIVEIRA, E. S.; ALVES, C. E.; DOUHI, N.. A percepção dos moradores sobre coleta seletiva na comunidade de Terra Nova do Piquiri, município de Assis Chateaubriand-PR.

Revista Uniabeu, v.5, n.9, 2012.

OLIVEIRA, N. R.; LACERDA, P. S. B. L.; KLIGERMAN, D. C.; OLIVEIRA, J. L. M.. Revisão dos dispositivos legais e normativos internacionais e nacionais sobre gestão de medicamentos e de seus resíduos. Ciência \& Saúde Coletiva, v.24, n.8, p.2939-2950, 2019.

PEDRINI, A. G.; SILVA, E. R.; RIBEIRO, I. C.; LEITE, M. C. A. M.;
AGUIAR, M. R. M. P.; ROCHA, P. E. D.; GUERRA, R. T. Metodologias em Educação Ambiental. Petrópolis: Vozes, 2007.

SOLIANI, R. D.; KUMSCHLIES, M. C. G.; SCHALCH, V.. A gestão de resíduos sólidos urbanos como estratégia de sustentabilidade. Revista Espacios, v.40, n.3, 2019.

SOUSA, S. S.; SILVA, I. L. S.; REGO FILHO, A. T. C.; LEMOS, E. J. S.; MEIRA, R. C. S.. Percepção dos moradores sobre a gestão dos resíduos sólidos no bairro Jardim Santarém, em Santarém, Pará, Brasil. In: SIMPÓsIO INTERNACIONAL DE QUALIDADE AMBIENTAL, 10. Anais. Porto Alegre, 2016.

THODE FILHO, S.; MACHADO, C. J. S. M.; VILANI, R. M.; PAIVA, J. L.; MARQUES, M. R. C.. A logística reversa e a política nacional de resíduos sólidos: desafios para a realidade brasileira. Revista Eletrônica em Gestão, Educação e Tecnologia Ambiental, v.19, n.3, p.529-538, 2015.

A CBPC - Companhia Brasileira de Produção Científica (CNPJ: 11.221.422/0001-03) detém os direitos materiais desta publicação. Os direitos referem-se à publicação do trabalho em qualquer parte do mundo, incluindo os direitos às renovações, expansões e disseminações da contribuição, bem como outros direitos subsidiários. Todos os trabalhos publicados eletronicamente poderão posteriormente ser publicados em coletâneas impressas sob coordenação da Sustenere Publishing, da Companhia Brasileira de Produção Científica e seus parceiros autorizados. Os (as) autores (as) preservam os direitos autorais, mas não têm permissão para a publicação da contribuição em outro meio, impresso ou digital, em português ou em tradução. 